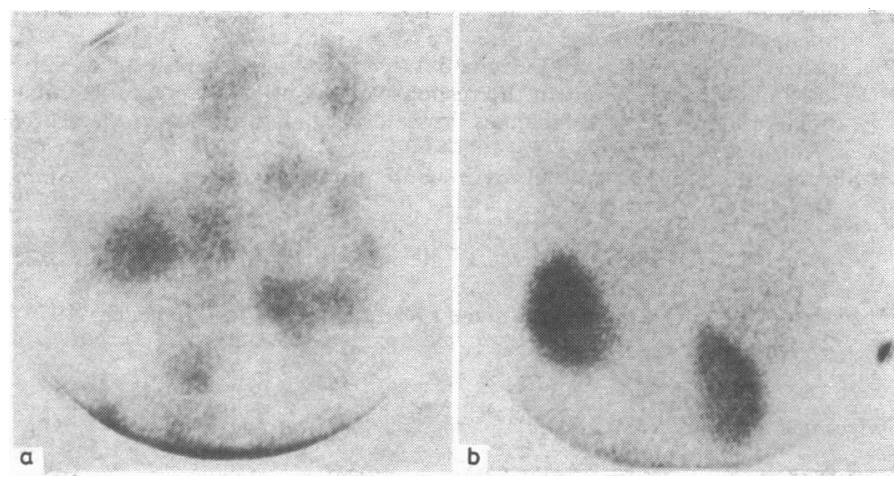

(a) Posterior image obtained using ${ }^{131}$ I-meta-iodobenzylguanidine. (b) Posterior renal image obtained using ${ }^{9 \theta} \mathrm{Tc}^{\mathrm{m}}$ - dimercaptosuccinic acid showing displacement and flattening of right upper pole.

procedures such as computed axial tomography may be helpful but are less successful in the $10 \%$ of tumours that are extraadrenal, multiple, or malignant. Use of intravenous contrast and selective venous sampling may be dangerous. In diseases known to be associated with phaeochromocytoma demonstration of adrenomedullary abnormalities by a simple non-invasive screening test would be useful.

${ }^{131}$ I-meta-iodobenzylguanidine can also be used to irradiate tumour tissue selectively; this is analogous to the use of ${ }^{131} I$ iodide in the treatment of differentiated thyroid malignancy.
Measurement of the uptake of ${ }^{131}$ I-meta-iodobenzylguanidine in our patient permitted calculation of the tumour radiation $\stackrel{\mathbb{Q}}{\Omega}$ dose; a therapeutic dose was subsequently given intravenously $c$ as a palliative measure. A similar patient has been treated at the $\bar{\sigma}$ University of Michigan. ${ }^{4}$

Using ${ }^{131}$ I-meta-iodobenzylguanidine offers a safe, specific, non-invasive procedure for localising phaeochromocytoma. \& Thirty-two such tumours have been correctly identified (Dr Shapiro, University of Michigan Medical School, personal communication). This may prove to be the initial investigation when phaeochromocytoma is suspected on clinical and biochemical evidence before more invasive investigations are undertaken.

We thank Miss P Tippett, Dr J Middleton, and Dr P Woods for blood and urinary catecholamine measurements.

\section{References}

1 Wieland DM, Wu J-I, Brown LE, Mangner TJ, Swanson DP, Beierwalte WH. Radiolabelled adrenergic neuron-blocking agents : adrenomedullary imaging with [131]I iodobenzylguanidine. F Nucl Med 1980;21:349-53.

2 Sisson JC, Frager MS, Valk TW, et al. Scintigraphic localisation of phaeochromocytoma. N Engl F Med 1981 ;305:12-7.

3 Sutton MStJ, Sheps SG, Lie JT. Prevalence of clinically unsuspected phaeochromocytoma. Mayo Clin Proc 1981 ;56:354-60.

Beierwaltes WH. New horizons for therapeutic nuclear medicine in 1981 f Nucl Med 1981 ;22:549-54.

(Accepted 30 fuly 1982)

\title{
Sudden large and periodic changes in heart rate in healthy young men after short periods of exercise
}

\author{
SHEILA JENNETT, J F LAMB； P TRAVIS
}

\begin{abstract}
The instantaneous heart rate and respiratory pattern were recorded immediately after brief periods of exercise in 41 healthy male students. Recordings were taken with the subjects both supine and standing. More than half of these subjects showed oscillatory heart changes when recovering supine but not when standing. During these oscillations the heart rate slowed suddenly by more than 30 beats/min; the oscillations had a period of 4 to 8 seconds, and they continued for half to two minutes. The $P$ waves of the electrocardiogram were decreased during the slowing, consistent with increased vagal activity. When these oscillations occurred they each followed the start of an inspiration with the same latency as in respiratory sinus arrhythmia; unlike respiratory sinus arrhythmia, however, they did not occur after every inspiration but varied from $1: 1$ to $1: 3$ oscillations:breaths. They were not usually stopped by breath holding but were reduced or abolished by procedures which reduced venous return.

This pattern of oscillations-"vagushalt"-seems to be
\end{abstract}

Institute of Physiology, University of Glasgow, Glasgow G12 OSE SHEILA JENNETT, MD, PHD, reader in physiology

Department of Physiology and Pharmacology, University of St Andrews, St Andrews, Fife KY16 9TS

J F LAMB, MB, PHD, Chandos professor of physiology

P TRAVIS, BSC, medical student different from respiratory sinus arrhythmias, and central venous pressure may contribute to the phenomenon. Although it is not widely recognised, vagushalt is probably very common and possibly its occurrence may change in disease.

\section{Introduction}

After brief periods of exercise the instantaneous heart rate often fluctuates.in an oscillatory manner while it is returning to the normal resting heart rate. ${ }^{1-3}$ Wenckebach ${ }^{4}$ described the sudden lengthening of the $R-R$ interval seen during such fluctuations as "bremsungen" (brakings). Kauf ${ }^{1}$ observed two patterns of return of the heart rate to normal in subjects recovering in the supine position: the first corresponded to a sinus arrhythmia associated with the breathing cycle, whereas the second showed irregular changes, which he thought were not related to every breath. These latter he called the "vagushalt" phenomenon.

In an earlier study of subjects recovering supine from exercise large "saw toothed" oscillations were observed in most young students examined, ${ }^{2}$ and they were not obviously related to respiration. Davies and Neilson ${ }^{3}$ reported a similar study but with continuous recording of tidal volumes and with their subjects standing during recovery. They found similar large oscillations of heart rate in five of their 10 subjects but concluded that this was a form of respiratory sinus arrhythmia because there was always a one-to-one relation and a constant phase lag between the breathing and the heart rate cycles. 
This study repeats and extends the earlier work. The breathing pattern was recorded continuously as well as the heart rate.

\section{Methods}

The heart rate and respiratory pattern were recorded in two series of healthy male students aged 17 to 26 years; 18 were in the first series and 23 in the second.

Self-adhesive chest leads were used to record heart rate: the electrocardiogram (ECG) triggered a Devices instantaneous rate meter; in the second series the ECG itself was also recorded to serve as a continuous check on the reliability of the heart rate reading as well as to observe any changes in the waveforms. In most cases the respiratory pattern was recorded by pneumotachograph (air flow in both series; and inspired tidal volume also in the first series) and in some by a nasal thermistor.

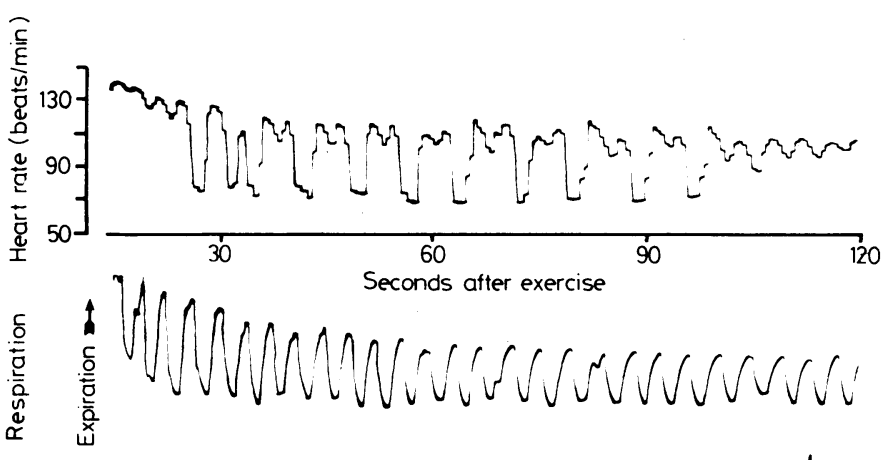

ECG

FIG 1-An example of the vagushalt phenomenon in a subject lying supine after a brief period of exercise: ECG trace, respiration, and computed heart rate. Note on the computed heart rate the saw-tooth shape of the waveform and that the fastest and slowest rates do not vary during recovery-that is, the oscillation occurs between fixed upper and lower limits. Respiratory sinus arrhythmia can be seen on the upper record before, between, and after the brakings. These brakings occur in relation to three consecutive breaths at the start of the record, thereafter after every second breath. The delay between the beginning of inspiration and minimum heart rate is 3.5 seconds.

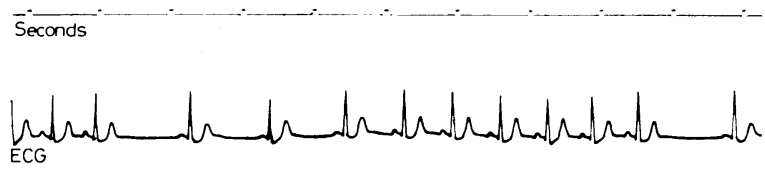

FIG 2-Record showing details of the ECG changes during a braking. Note the abrupt lengthening of the $R-R$ interval and the coincidental decrease of the $P$ wave.
The subjects were required to work for one minute, at 200 watts, on a bicycle ergometer so that their heart rate reached at least 150 beats/min. The subject then stopped pedalling and lay down while his heart rate and breathing pattern during recovery were recorded. The procedure was repeated but the subject recovered standing up. Some subjects repeated the procedure once more with supine recovery. Some were studied more than once.

In some subjects we performed procedures designed to determine the effect of changes in venous return on the heart rate pattern during recovery in the supine position. These procedures were venous occlusion in both thighs (bandages or cuffs inflated to $50 \mathrm{~mm} \mathrm{Hg}$ ) or the Valsalva manoeuvre (blowing against a column of mercury to $40 \mathrm{~mm} \mathrm{Hg}$ ), or both. Some subjects were asked to hold their breath, keeping an open glottis, to interrupt breathing without intrathoracic pressure changes (this proved difficult for some of them).

\section{Results}

\section{INCIDENCE AND CHARACTERISTICS OF THE PHENOMENON}

The period of exercise was short, so the recovery period was also short; typically the heart rate had returned to the resting value after three to four minutes. In 12 of the 41 subjects in the two series the heart rate returned smoothly to the resting value. In the remaining 29 (71\%) several "brakings" of the heart rate occurred during recovery in the supine position. A braking was defined as a sharp fall in rate of more than 30 beats/min-that is, an increase in R-R interval of more than 0.5 second (fig 1 ). Braking did not occur in these subjects in the standing position.

Typically (fig 1) brakings began at a mean heart rate of about 100 beats/min, lasted for about one minute, and subsided as the preexercise heart rate was approached. The ECG trace showed the sudden lengthening of the R-R interval (as, for example, in fig 2, from 0.6 to 1.4 seconds-that is, to 43 beats $/ \mathrm{min}$ ) and the decrease in the amplitude of the $P$ wave during the braking. This finding confirmed other reports ${ }^{3}$ and was consistent with a large release of acetylcholine. ${ }^{5}$

The duration of the sequence of brakings varied greatly between the subjects. In 10 subjects in series $2(43 \%)$ the sequence was sustained for more than half a minute. In the others in series 2 who showed the phenomenon brakings were similar but lasted for shorter periods. The cycles of large amplitude containing a steep fall in heart rate are referred to hereafter as vagushalt cycles.

\section{RELATION TO BREATHING CYCLE}

The delay from the beginning of the immediately preceding inspiration to the braking was examined. This was consistent in any one individual and was about 3 seconds.

In any one subject the delay from the beginning of inspiration to the braking in a vagushalt cycle was not significantly different from the delay to the slowest rate in a respiratory sinus arrhythmia cycle. In the subject depicted in fig 1 the mean delay for the vagushalt cycle was 3.5 seconds and for the respiratory sinus arrhythmia cycle 3.8 seconds, and these were not significantly different $(p>0 \cdot 1)$. Vagushalt could occur after every inspiration or after every second or third

FIG 3-Breath holding on vagushalt. During periods of heart rate fluctuation subjects were asked to stop breathing either after a normal inspiration $(a)$ or a normal expiration (b) but without raising intrathoracic pressure. Vagushalt was not affected.

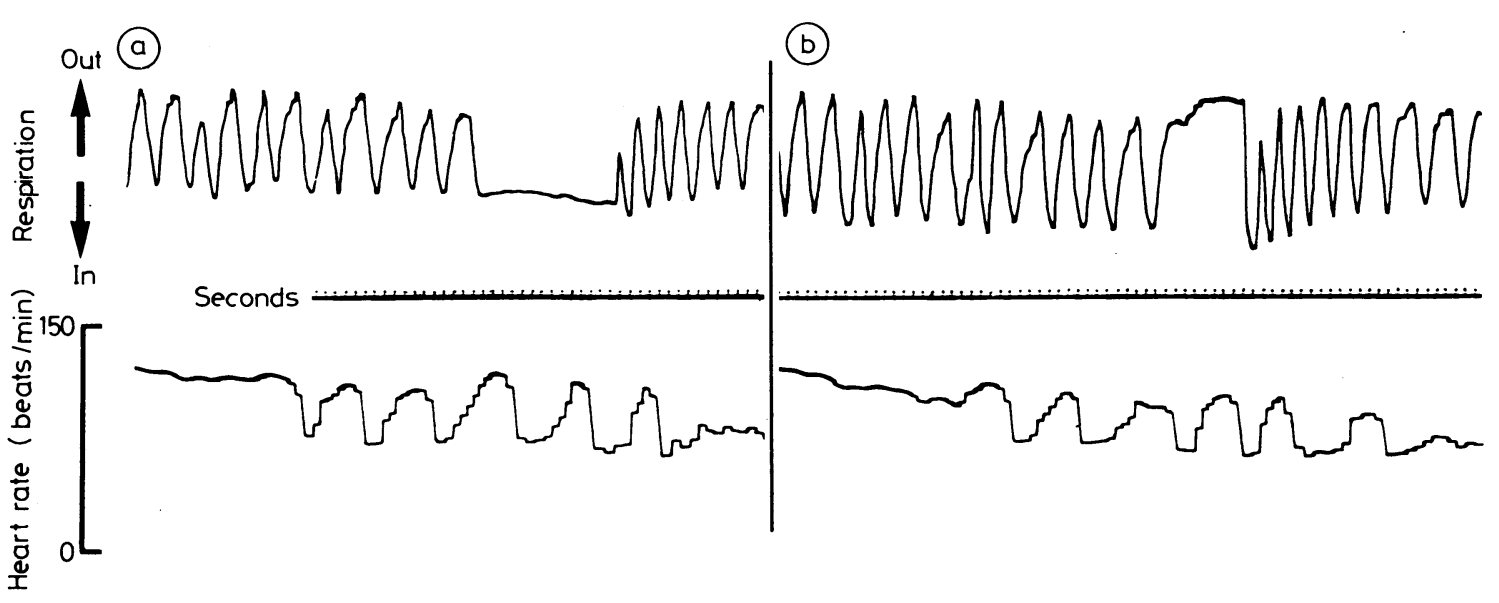


inspiration; some subjects showed varying ratios within the same sequence of oscillations. Nevertheless, there was a consistent delay from the start of a preceding inspiration.

Breath holding was successfully performed during the vagushalt sequence by seven subjects. Six of them showed a continuation of the vagushalt while they were holding their breath (fig 3 ).

\section{EFFECT OF PROCEDURE ALTERING VENOUS RETURN}

Comparison of supine and standing studies-Subjects who showed the phenomenon when supine did not show it when standing (fig 4). Not all subjects, however, showed the phenomenon repeatedly when studied supine a second time.

Venous occlusion was carried out on five subjects during a sequence of vagushalt. In all cases the oscillations were abolished and in four of the subjects they returned on releasing the occlusion (fig 5).

Valsalva manoeuvre-This also abolished the oscillations, but this feature is a complex of effects on venous return, of breath holding, and of altered baroreceptor inputs.

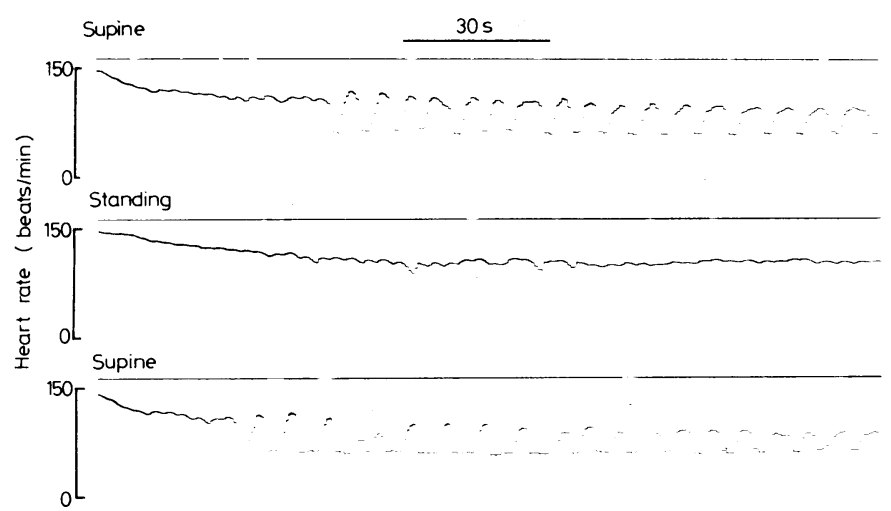

FIG 4-Posture on vagushalt. The same subject was examined once on three separate occasions. When lying supine after exercise he showed a pronounced vagushalt phenomenon; when standing he showed only respiratory sinus arrhythmia.
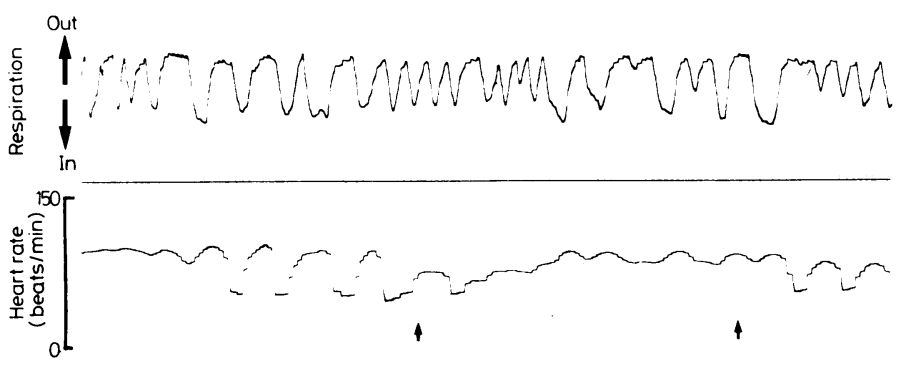

FIG 5-Venous cuffs on vagushalt. The subject was exercised as usual. During recovery cuffs were placed round the upper thigh and rapidly inflated at the times indicated on the record and then released as shown. Vagushalt was stopped during the inflation, and respiratory arrhythmia disclosed.

\section{Discussion}

This work started originally as a class experiment with students. ${ }^{2}$ We expected then that after a brief period of exercise the heart rate would fall smoothly to the resting level. In our experience this has proved to be unusual when the subjects are lying down, although it does occur when they stand or sit during recovery. Most young healthy men, lying supine after exercise, show a series of large and sudden swings in heart rate, starting when the mean rate has fallen to around 100 and continuing for up to two minutes.

Davies and Neilson, who repeated our earlier experiments, ${ }^{36}$ concluded that the oscillatory phenomenon was simply an exaggerated form of respiratory sinus arrhythmia. They found oscillations, conforming to vagushalt as defined above, in five out of 10 subjects even though they examined them standing after exercise. This difference from our own findings remains unexplained. In their subjects the relation between the heart rate oscillations and the breathing cycle was also reported to be always $1: 1$. Perhaps if they had studied more than five subjects who showed the phenomenon, or studied them supine, they might have encountered $2: 1$ or 3:1 ratios (figs 1 and 3).

Our own results suggest that vagushalt is a phenomenon separate from respiratory sinus arrhythmia, ${ }^{7}$ although we have shown it to be linked in the sense that it always bears the same time relation to a respiratory cycle, although not to all respiratory cycles.

The continuation of vagushalt cycles during breath holding is an interesting, newly observed phenomenon, which appears to conflict with the findings of Davies and Neilson, ${ }^{3}$ who found that similar oscillations disappeared. Interpretation is complicated by the possible direct effects of central respiratory neurone activity, in the absence of actual lung movement, on vagal cardiac activity. ${ }^{8}$ The phase of the respiratory cycle certainly alters baroreflex sensitivity during normal breathing. ${ }^{9}$

The greater occurrence of vagushalt when central venous pressure is augmented by lying down and its inhibition by reducing venous return suggest that central venous pressure is an important contributor to the phenomenon.

A possible explanation of this phenomenon is that the system controlling vagal activity has a natural periodicity of between 5 and 10 cycles per minute and that its stability is reduced by raised central venous pressure. The periodicity which is observed during vagushalt is then a consequence of entrainment by the respiratory frequency or by submultiples of it; hence the relation'ship to breath cycles may be $1: 1,1: 2$, or $1: 3$.

One of the curious features of this phenomenon is that, although we believe it to occur very often, it is not widely recognised. Since becoming aware of it, we have observed it often in ourselves and in others when lying down after even the mildest of efforts. We think that it does not occur after more severe exercise than that which we studied in these series. It may also occur during long-term sleep records in normal subjects ( $\mathrm{P}$ Travis, unpublished observations).

This lack of awareness of the phenomenon may be due to several factors: few ECG records are taken in the precise circumstances necessary for its discovery; few are ever taken over several minutes; measurements of mean heart rate counted over 10-15 seconds miss the oscillations.

Once aware of vagushalt clinicians will probably find it often. Its occurrence may change in the presence of different diseases, and this suggestion is strongly supported by the finding that enforced bed rest for a short period caused vagushalt cycles to disappear in Davies and Neilson's series. ${ }^{3}$

Requests for reprints should be sent to Dr J F Lamb.

\section{References}

1 Kauf E. Untersuchungen über das Verhalten des Herzens nach Muskelarbeit. Wiener archiv für innere Medizin 1923;5:567-80.

${ }^{2}$ Lamb JF. Oscillation of heart rate after exercise in man. $\mathcal{F}$ Physiol 1963; 168:55-6P.

${ }^{3}$ Davies CTM, Neilson JMM. Disturbance of heart rhythm during recovery from exercise in man. $f$ Appl Physiol 1967;22:943-6.

4enckebach KF. Die unregelmassige Herztatigkeit und ihre Klinische Bedeutung. Leipsiz: 1914.

${ }^{5}$ Hoffman BF, Suckling EE. Cardiac cellular potentials: effect of vagal stimulation and acetylcholine. Am $\mathcal{F}$ Physiol 1953;173:312-20.

6 Davies CTM, Neilson JMM. Sinus arrhythmia in man at rest. $\mathcal{F} A p p l$ Physiol 1967;22:947-55.

${ }^{7}$ Melcher A. Respiratory sinus arrhythmia in man. Acta Physiol Scand [Suppl] 1976;435.

${ }^{8}$ Potter EK. Inspiratory inhibition of vagal responses to baroreceptor and chemoreceptor stimuli in the dog. $\mathcal{F}$ Physiol 1981 ;316:177-90.

${ }^{9}$ Eckberg DL, Kifle YT, Roberts VL. Phase relationship between normal human respiration and baroreflex responsiveness. f Physiol 1980;304: 489-502.

(Accepted 29 fuly 1982) 